\title{
Escasa utilidad del examen genital para identificar abuso sexual en niñas prepuberales
}

\author{
Little use of genital examination to identify sexual abuse in prepubertal girls \\ Berkoff MC.y col. JAMA. 2008 Dec 17;300(23):2779-92
}

\section{Objetivo}

Establecer la utilidad diagnóstica de los hallazgos del examen genital en niñas prepuberales para identificar abuso sexual no reciente.

\section{Diseño}

Revisión sistemática.

Fuente

MEDLINE (1966 a 2008) y revisión manual.

Selección de estudios y extracción de datos

Dos evaluadores independientes seleccionaron estudios pri- marios en inglés que hubieran evaluado signos de abuso sexual y/o trauma del himen en niñas prepuberales y contuvieran información para realizar cálculos sobre las características operativas de los estudios, realizar análisis estadísticos, técnicas de examen físico reproducibles y estándares de referencia aceptables para determinar si la niña fue abusada. Se utilizaron como palabras clave abuso sexual de niños combinado con sensibilidad y especificidad, genital, mujer, examen físico y diagnóstico.

\section{Resultados Principales}

Sólo se seleccionó un artículo. Los resultados se aprecian en la tabla1.

Tabla 1: Características operativas de los signos sospechosos de abuso en el exámen físico

\begin{tabular}{c|c|c|c|c} 
& Sensibilidad (\%) & Especificidad (\%) & CPP (95\% IC) & CPN (95\% IC) \\
\hline Flujo vaginal & 11 & 96 & 42,7 (1,2 a 6) & $0,93(0,88$ a 0,98$)$ \\
\hline $\begin{array}{c}\text { Diámetro de la apertura del } \\
\text { himen > 6.5 mm }\end{array}$ & 29 & 86 & 2.0 (1,3 a 3,2) & $0,83(0,74$ a 0,93$)$ \\
\hline Cortes transversales & 1 & 100 & 3,1 (0,13 a 76) & $0,99(0,98$ a 1$)$ \\
\hline Muescas profundas & 1 & 100 & 5,2 (0,25 a 108) & $0,99(0,97$ a 1$)$ \\
\hline Perforaciones & 1 & 100 & 3,1 (0,13 a 76) & $0,99(0,98$ a 1$)$ \\
\hline
\end{tabular}

CPP: coeficiente de probabilidad positivo CPN: coeficiente de probabilidad negativo IC: Intervalo de confianza

La presencia de flujo vaginal y/o un diámetro de la apertura himeneal mayo a $6,5 \mathrm{~mm}$ en posición genupectoral fueron los únicos hallazgos estadísticamente asociados a abuso sexual.

\section{Conclusiones}

Los hallazgos del examen físico no fueron concluyentes en forma individual a la hora de definir abuso sexual no reciente en niñas prepuberales. Sin embargo debería elevarse la sospecha en aquellas niñas prepuberales que tengan flujo vaginal, cortes transversales, muescas profundas y perforaciones en la región posterior del himen (hora 4 a 8 ) ya que dichos hallazgos son extremadamente infrecuentes en niñas prepuberales sin historia de trauma genital por abuso sexual.

Palabras claves: Abuso sexual, niñas prepuberales,examen físico. Keywords: Sexual abuse, prepubertal girls, physical examination. Fuentes de financiamiento: ninguna.

\section{Comentario}

La Organización Mundial de la Salud (OMS) estima que $40 \mathrm{mi}-$ llones de niños sufren maltrato en el mundo. El abuso sexual es una de las formas de maltrato infantil ${ }^{1}$ y se define como la participación de un niño en una actividad sexual que no comprende plenamente, a la que no es capaz de dar consentimiento, o para la que, por su desarrollo no está preparado o bien que infringe las leyes o los tabúes sociales. ${ }^{2}$

En la Argentina, la legislación obliga a los profesionales de la salud a denunciar los hechos de abuso sobre menores o incapaces. ${ }^{3}$ Esto hace imprescindible que el equipo de salud pueda reconocer las conductas y los hallazgos del examen físico sospechosos de abuso sexual.

Los resultados de esta revisión indican que ningún signo aislado puede corroborar el diagnóstico, aunque la presencia com- binada lo haría más probable.

\section{Conclusiones de la comentadora}

Si bien el estudio no logró demostrar la existencia de lesiones que definan indiscutiblemente abuso sexual, permitió encontrar algunos hallazgos que incrementan la sospecha, tales como la presencia de flujo vaginal y las muescas, perforaciones y cortes transversales en el himen. También permitió definir los hallazgos frecuentes en el examen genital de las niñas prepuberes que no han sido abusadas. Con respecto a las lesiones como el diámetro de la apertura del himen, hay que tener cuidado ya que son poco precisas.

Mercedes Mutchinick [ Servicio de Medicina Familiar y Comunitaria del Hospital Italiano de Buenos Aires ]

Mutchinick M. Escasa utilidad del examen genital para identificar abuso sexual en niñas prepuberales. Evid Actual Práct Ambul 13 (2) 52 . Abr-Jun 2010. Comentado de: Berkoff MC y col. Has this prepubertal girl been sexually abused? JAMA. 2008 Dec 17;300(23):2779-92. Review. PubMed PMID: 19088355

\section{Referencias}

1. Ferreira, A; Beltran, M y col.Maltrato infantil y abuso sexual en la niñez. Programa AIEPI. OPS-OMS, 2004. Disponible en: http://www.paho.org/spanish/ad/fch/ca/si-maltrato1.pdf [con acceso el 25-01-2010]

2. MINSA. Atencion integrada a las enfermedades prevalentes de la infancia. Capitulo III. Atención niño de 0 a 2 meses. Páginas 17 a 56 . Programa AIEPI, 2008

3. Poder Legislativo Nacional, Ley 24.417 de Protección contra la Violencia Familiar (1994), decreto reglamentario 235/96. 